\title{
Study on Dune Morphology in Computer Mapping Based on 3S Technology
}

\author{
Zhidan $\mathrm{BA}^{1}$ \\ College of Tourism and Geographical Sciences, Jilin Normal University, China
}

\begin{abstract}
Take the parabolic dune of Hobq desert in Inner Mongolia as research object. Based on the GIS platform by using differential GPS data and spatial interpolation to generate DEM, then using Multi-periods high resolution images to acquire the environmental background, at the same time combine with regional wind regime and vegetation condition to measure and analyze the morphology of the parabolic dune. The result shows that the parabolic dune showed U shape in plane, and dune arms point to the west which was also wind direction. The windward slope of longitudinal profile is gentler, while leeward slope is steeper. And cross section wasn't symmetric. The dune's average moving speed is 11.76 $\mathrm{m} / \mathrm{yr}$. Desert ridge line's medial axis direction is WNW-ESE, in accord with the direction of prevailing wind and resultant drift potential. Artemisia Ordosicas mainly distribute on leeward slope, two arms, and the plane ground between them, and the annual average vegetation coverage decreased $0.95 \%$. In the long-term effect of resultant wind, the dune keeps moving forward and Artemisia Ordosica between two arms show gradual natural stage recovery which presented zonal distribution. $3 \mathrm{~S}$ technology has already become important research method in modern Aeolian sand morphology.
\end{abstract}

Keywords. Parabolic dune, Morphological, 3S technology, Hobq

\section{Introduction}

Parabolic dune is u-shaped or horse shoe shaped in plane, the two arms of the dune extend to the upper wind drift, and the windward slope is gently and concave, while the leeward slope is steep and convex [1-2] and from the elongation of blowout hollows [3]. At present, research on the dynamics of parabolic dunes has focused on several key areas including dune distribution and morphology [4-6]; timing of past dune activity [7-8]; rates of migration [9]; internal structure [10]; and contemporary processes [11].

$3 \mathrm{~S}$ technology is short for remote sensing (RS), Geography information system (GIS) and Global positioning systems (GPS) [12], and it is an important method in modern geography research [13]. At present, the most common way to acquire the 3D data of Aeolian geomorphology in moderate-small scale is ground measurement by using GPS [14], electronic total station [15], 3D laser scanner [16] and LIDAR [17]. Digital elevation model (DEM) is the basis of geography analysis [18], effective method to research the surface morphological character, and its change law [19].

To address these issues, the spatial and temporal patterns of sediment transport at monthly to annual timescales were documented across an active parabolic dune. This

1 Corresponding Author, College of Tourism and Geographical Sciences, Jilin Normal University, China; e-mail: bazhidan1999@163.com. 
was accomplished by repeat measurements from RTK GPS over a four-year period and from a grid of erosion pin over a two-year period. These data were used to map the morph dynamics of the dune and to develop indices of sediment transport, which are compared with nearby meteorological data to examine the effects of variability in atmospheric conditions on sediment transport. In addition, this paper takes the typical parabolic dune in the edge of Hobq desert as the research object, and use $3 \mathrm{~S}$ technology to do the research in morphological changes of the dune.

\section{Study Area and Data Acquisition}

Hobq desert is in the northern part of the east-west uplift belt in Ordos Plateau, and locate in Hangjinqi, Dalateqi and Zhungerqi of Yikezhao league in Inner Mongolia $\left(109^{\circ} 30^{\prime}-110^{\circ} 45^{\prime} \mathrm{E}, 39^{\circ} 48^{\prime}-40^{\circ} 33^{\prime} \mathrm{N}\right)$. It is higher in South than North and surrounded by the yellow river in West, North and East. It is temperate arid and semi-arid zone, 25 to 35 days of strong wind a year, annual mean temperature is $7.4{ }^{\circ} \mathrm{C}$, annual precipitation is $249 \mathrm{~mm}$, average annual evaporation $2450 \mathrm{~mm}$, and frostless period is 156 days. The moving dunes are densely distributed in the northern part of the desert, while in the southern scab rock, flaky moving dune, shrub and Nabkha are distributed and among them there are some parabolic dunes.

We use Leica 1230 differential GPS to do the morphological measurement; the instrument's marked precision in horizontal is $10 \mathrm{~mm}+1 \mathrm{ppm}$, and vertical is $20 \mathrm{~mm}+1$ ppm. We collected the information, such as the coordinate system and central meridian about the research area before measuring. We embedded more than three marked stone where the blown sand does not influence around the dune as the control points which are used to check the random error when continuous measuring and in order to cooperate with the total station. To measure the control points in static model of the GPS simultaneous, Since all the surveying and mapping data accumulated in Early China were Beijing 54 coordinates, in order to make comparative analysis with the data results of existing coordinates, so change the WGS-84 coordinate system to Beijing- 54 . Using the dynamic model to measure the WGS-84 coordinates of the control points with moving station and then change them to Beijing-54 coordinates by seven-parameter method, finally measuring the detail points of the dune. The data used in this paper were collected in Oct 2009; May, Oct, and Dec 2010; May, Jul, Sep 2011. The error of the data which meet the precision requirement is less than $20 \mathrm{~mm}$.

In order to research the change of vegetation coverage around the dune, the remote sensing data were needed to analyze it in large time-span, such as Quick Bird image in Aug 2005, Feb 2007, and May 2010. The reason is to try to ensure that the measurements are close to the dune morphology, because commercial companies do not have data from other times.

\section{Results and Analysis}

\subsection{DEM Acquisition and its Features}

It is necessary to generate DEM data by spatial interpolation, because the data acquired from the differential GPS is spatial discrete coordinates, and this paper use the 
neighborhood interpolation method of 3D Analyst module of ArcGIS 9.3 to realize it, the neighborhood interpolation uses an algorithm that finds the subset of input samples closest to the query point and applies weights to these samples proportionally based on the region size to interpolate. We use the elevation points by spatial interpolation to generate the raster surface, and then generate contour and finally generate TIN DEM (Figure 1).

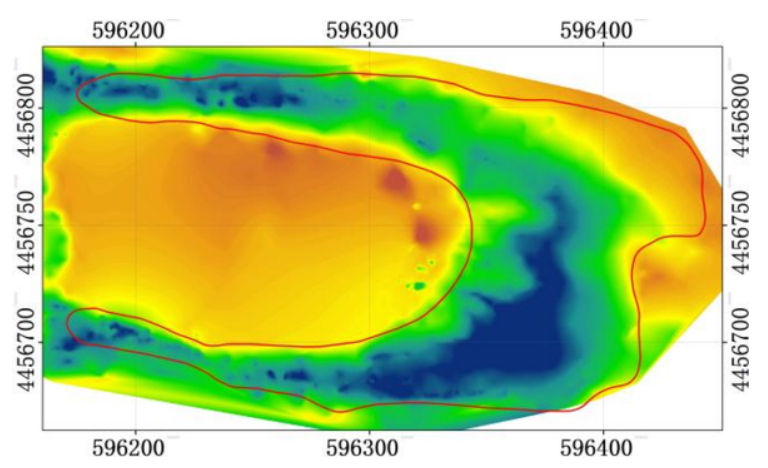

Figure 1. DEM of parabolic.

According to the study area investigation and DEM analysis, the parabolic dune showed U shape in plane, and dune arms where grow Artemisia Ordosica pointing to the west in accordance with up windward. The windward slope is concave, while the leeward is convex. Until now, the length of the dune is $262.45 \mathrm{~m}$, width is $147.09 \mathrm{~m}$, relative height is $5.73 \mathrm{~m}$, the length of the arms is $168.66 \mathrm{~m}$, the inner width between arms is $91.36 \mathrm{~m}$, the plane area is $18600.58 \mathrm{~m}^{2}$, and the volume is $40239.06 \mathrm{~m}^{3}$. The toe of the windward slope outcrops soil layer, and in the middle of it develops four blowouts which developed and expanded. While in the leeward slope, the gradient of sand fallen slope is increasing, and the slip face is becoming higher. According to the length-width ratio, it is leaf shape (LLWR is between1.0 to 3.0) has the length-width ratio features of relatively mature.

In the research period, the dune has been moving to West. The toe of windward slope advanced $23.22 \mathrm{~m}(11.61 \mathrm{~m} / \mathrm{yr})$, while the leeward advanced $23.52 \mathrm{~m}$ (11.76 $\mathrm{m} / \mathrm{yr})$, and relative height has decreased $0.78 \mathrm{~m}(0.39 \mathrm{~m})$. The plane area of dune has increased $1901.70 \mathrm{~m}^{2}\left(950.85 \mathrm{~m}^{2} / \mathrm{yr}\right)$, because nose moved along the prevailing wind direction, while arms relatively fixed. The volume decreased $840.78 \mathrm{~m}^{3}\left(420.34 \mathrm{~m}^{3} / \mathrm{yr}\right)$, because undulant underlying surface and a small amount of sand material being blown away.

\subsection{Profile and its Morphological Parameters}

Based on the DEM, extract and analyze the longitudinal and cross profile by means of using the 3D Analyst module in ArcGIS 9.3. That means using the Interpolate line tool to make sure the location and trend of profile line then generate the graph of profile line by using create profile graph tool.

As it is shown in the profile graph (Figure 2), the geomorphology units of longitudinal profile of the dune are flat ground in two arms, windward slope, dune top, and leeward slope. At present, the length of flat sandy land in two arms is $167.72 \mathrm{~m}$ where growth the Artemisia Ordosica. The length of windward slope is $46.54 \mathrm{~m}$, the 
surface of the slope is concave, the gradient is between $16^{\circ}$ to $21^{\circ}$, and in the bottom distributes some small wind-erosion residual frusta, and in top of the dune has strong wind erosion. The length of leeward is $32.71 \mathrm{~m}$; the gradient is between $27^{\circ}$ to $36^{\circ}$, the main body of dune move forward in the form of slip face collapse.

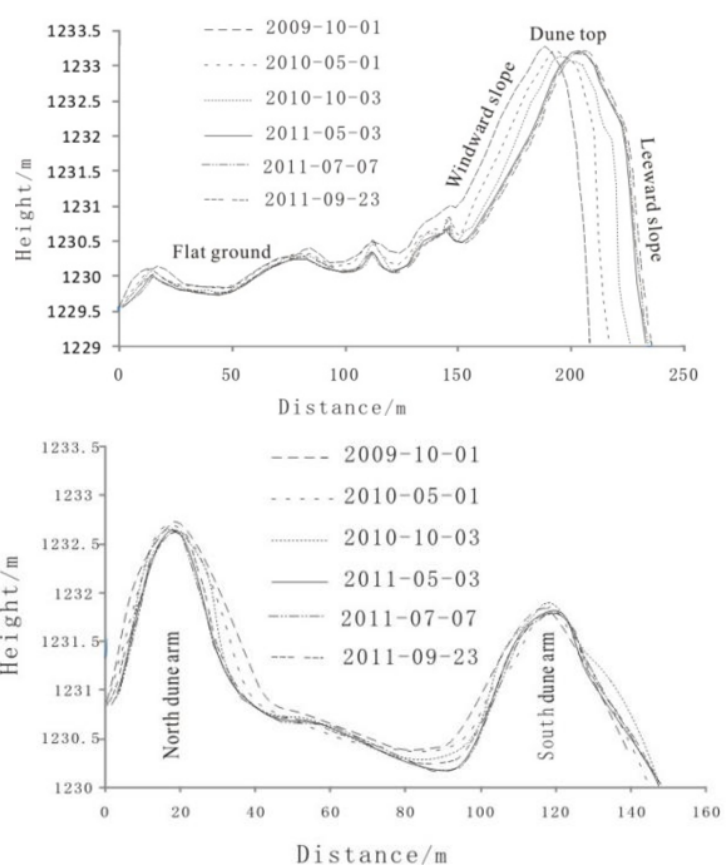

Figure 2. Profile of dune (left longitudinal profile; right, cross profile).

\subsection{Ridge Line of the Dune and Wind Regime Analysis}

Using the method mentioned above to extract the plan curvature of negative landform B. Fourthly, use the formula $[[[\mathrm{A}+\mathrm{B}]-[\mathrm{A}-\mathrm{B}] . \mathrm{abs}] / 2]$ to acquire the plan curvature of DEM without error. Lastly, adjust the threshold to extract the ridge line.

Ridge line is U shaped, and it has the characteristics of typical parabolic dune's ridge line. The axis is WNW-ESE. The ridge line moves forward along with the dune, and it advanced $22.50 \mathrm{~m}(14.21 \mathrm{~m} / \mathrm{yr})$.

\subsection{Morphological Changes and Vegetation Distribution}

Vegetation distribution characteristic is a significant factor to control the erosion-deposition pattern and to effect its formation and development. A little change of vegetation coverage can make great effect in dune morphology. The previous method to measure the vegetation coverage was using the GPS or electronic total station dotting the vegetation boundary and then sketch out the boundary in computers [19], while the vegetation coverage acquired mainly by sampling surveys estimated by researchers in the field.

According to the Quick bird image and interpretation graph (Figure.3), vegetation coverage of the dune has decreased from $36.81 \%$ in 2005 to $32.04 \%$ in 2010 . The main 
reason is that the dune moved forward and arms are elongating which makes the area of vegetation is increasing though the area of dune is increasing.
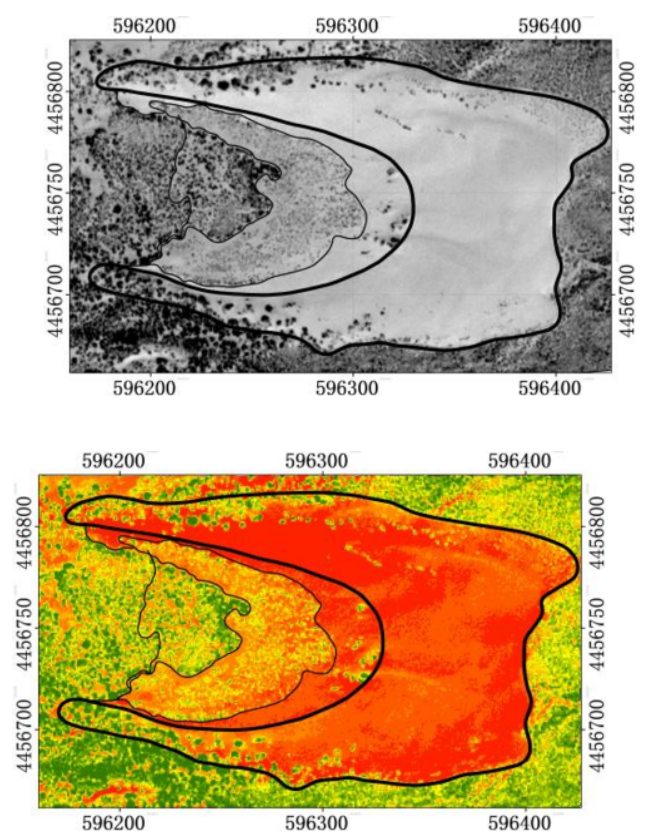

Figure 3. Quick bird panchromatic image and interpretation graph.

\section{Conclusion}

Based on the GIS platform, using the measured data acquired from differential GPS to generate DEM by spatial interpolation. The terrain factors and morphological parameters can be extracted effectively, in order to realize the quantitative research about Aeolian morphological changes.

The parabolic dune that we research showed U shaped in plane, the arms point to west which was also wind direction, windward slope is concave and leeward slope is convex. Because the dune is located in the edge of desert, the relative height is low; its move speed is fast and advanced $11.76 \mathrm{~m}$ annually. The plane area of dune has annual increased $950.85 \mathrm{~m}^{2}$ due to nose moved along the prevailing wind direction, while arms relatively fixed.

\section{Acknowledgments}

This research was funded by the National Natural Science Foundation of China (NO. 41871022). 


\section{References}

[1] $\mathrm{Wu} \mathrm{Z.} \mathrm{Geomorphology} \mathrm{of} \mathrm{wind-drift} \mathrm{sands} \mathrm{and} \mathrm{their} \mathrm{controlled} \mathrm{engineering,} \mathrm{Science} \mathrm{Press,} \mathrm{Beijing,}$ 1995.

[2] Zhu ZD, Wu Z, Liu S et al. Introduction to Chinese desert, Science Press, Beijing, 1980.

[3] Fernandez-Cascales L, Lucas A, Rodriguez S, et al., First quantification of relationship between dune orientation and sediment availability, Olympia Undae, Mars, Earth and Planetary Science Letters, 489(2018), 241-250.

[4] Wang P, Ma Q, Zhu YP, et al., Particle size characteristics of surface sediments of scrub sand piles and parabolic dunes in the Tokay Desert, Xinjiang and their depositional environment, Arid Zone Geography, 10(2021), 1-13.

[5] Yan NH, Liu HQ, et al., Research progress in morphology and evolution of the parabolic dunes, Journal of Desert Research, 30(2010), 801-807.

[6] Kathryn LR, Geoff JV, Tim DF. Urban sediment supply to streams from hill slope sources, Science of the Total Environment, 653(2019), 684-697.

[7] Dong YX, Huang DQ, A typical study of coastal barchans dune movement and morphological change, Geosciences, 34(2014), 863-869.

[8] John TK, Andrew JM, Claire W. Spatial and temporal patterns of suspended sediment transport in nested urban watersheds, Geomorphology, 336(2019), 95-106.

[9] Srivastava A, Thomas DSG, Durcan JA. Holocene dune activity in the thar desert, India, Earth Surface Processes and Landforms, 44(2019), 0197-9337.

[10] Tripaldi A, Mehl A, Zarate MA. Parabolic mega dunes in a subtropical quaternary inland dune field, southwestern pampas, Argentina, Geomorphology, 321(2018), 103-116.

[11] Cheng RT, Cai LF. Ship borne radar calibration technology based on differential GPS and radar beacon, Ship Electronic Engineering, 41(2021), 76-79+88.

[12] Zhang LW, Lu HF. Summary of application status of 3S technology in coal mine geological hazards, Software Engineering and Applications, 10(2021), 549-556.

[13] Emmanouil P, Konstantinos XS, Melpomeni Z, et al., Synergistic approach of remote sensing and gis techniques for flash-flood monitoring and damage assessment in thessaly plain area, Greece, Water, 11(2019), 448.

[14] Zhong YF, Yi MS. Application of 3D laser scanner in mine survey, Low-carbon world, 11(2021), 66-67.

[15] Baptista PC, Cunha TR, Matias AG, et al. New land-based method for surveying sandy shores and extracting DEMs: the INSHORE system, Environmental Monitoring and Assessment, 182(2011), 243-257.

[16] Hugenholtz $\mathrm{CH}$. Topographic changes of a supply-limited inland parabolic sand dune during the incipient phase of stabilization, Earth Surface Processes and Landforms, 35(2010), 1674-1681.

[17] Liu B, Yu Y, Jiang M. Review of advances in LIDAR detection and 3D imaging, Photoelectric Engineering, 46(2019), 21-33.

[18] Keck H, Fel De V, Drahorad SL, et al. Biological soil crusts cause subcritical water repellency in a sand dune ecosystem located along a rainfall gradient in the NW Negev desert, Israel, Journal of Hydrology and Hydromechanics, 64(2016), 133-140.

[19] Chen XL, Li ZZ, Chen SJ et al., The morphological character research of parabolic dune-based on the date of differential gps survey. Journal of Fujian Normal University (Natural Science Edition), 26(2010), 84-89. 